\title{
Climate Policy: Analysis of ecological, technical and economic implications for international maritime transport
}

\author{
Sven Bode1), Jürgen Isensee2), Karsten Krause ${ }^{\left.3)^{*}\right)}$ \& Axel Michaelowa1) \\ 1) Hamburg Institute of International Economics \\ 2) Naval Architect, Consultant \\ 3) Free and Hanseatic City of Hamburg \\ *) Corresponding author: Eulenstr. 56, D-22765 Hamburg, karsten.Krause@sternpost.de
}

International Journal of Maritime Economics, 2002, Vol. 4, p.164-

\section{Abstract}

In 1997, the $3^{\text {rd }}$ conference of parties to the UN Framework Convention on Climate Change adopted the Kyoto Protocol as a consequence of increasing evidence of a manmade global warming of the atmosphere. Binding greenhouse gas emission reduction targets for industrialized countries were agreed upon. However, bunker fuel emissions from international shipping have so far been excluded from any commitment in the protocol. After looking at the magnitude of emissions from international shipping and likely trends, we make suggestions how shipping can be integrated into polices to control greenhouse gas emissions. The objective of policy instruments has to be the introduction of an effective and efficient stimulus for environmentally sound operational and technical improvements on existing and new ships. Consequently, the best solution would be for IMO to agree on a global shipping emissions target that would be comparable to targets of industrialized countries. However, for the time being, the introduction of a CDM type mechanism would be a promising step into the right direction.

Keywords : 1) climate policy, 2) greenhouse gases, 3) international shipping, 4) allocation of emissions, 5) policy instruments 6) technological options 


\section{INTRODUCTION}

Ship transportation is considered the most environmentally-sound mode of transport. In public opinion, environmental problems of ships seem to be linked to accidents, in particular of oil tankers. Emissions of local and global air pollutants through the burning of marine bunker fuels are a relatively new area of environmental concern. Thus, the emissions of the international merchant fleet has become an increasing focus of global and regional environmental policies. The integration of the shipping industry into the global climate policy regime is currently a new challenge for policy makers and the industry.

Climate protection has to be considered as a cross-sectional policy area, dependent on the coherence of environmental objectives in related policy areas, such as transport or trade regulation. In the last decade, international climate policy has become one of the most important elements of national and international environmental policies. International negotiations on climate change started in the late 1980s and resulted in the signatory of a Framework Convention on Climate Change (FCCC) at the UN Conference on Environment and Development in 1992. They culminated in the negotiation of the Kyoto Protocol in 1997. It will be the initial step towards a comprehensive global greenhouse gas regime. Bunker fuel emissions account for about $1,8 \%$ of the world's $\mathrm{CO}_{2}$ emissions in 1998 and are thus in the magnitude of OECD countries like France (1998: 1,6\%) or Australia (1998: 1,4\%) (OECD 2000b pp. $38+44)$.Bunker fuel emissions from international shipping and emissions from air transport have so far been excluded from any commitment in the Kyoto Protocol. While emissions from international aviation have been targeted by many environmental NGOs, and been subject of a special report of the Intergovernmental Panel on Climate Change (IPCC), international shipping has so far been neglected in the debate. However, corresponding to the discussion on aviation, air emission from ships is likely to be integrated into the existing climate regime over the next years. This is all the more true against the background of the successful climate negotiations in July 
2001 that paved the way to an international ratification of the Kyoto-Protocol. After looking at the magnitude of emissions from international shipping and likely trends, we make suggestions how this integration can be done in an economically efficient and politically feasible way.

Parallel to the debate on climate policy, international shipping is already experiencing the first effects of global warming. Ports in northern Canada are able to expand their shipping season and ship owners are exploring Arctic routes in order to bypass bottlenecks on established routes or to cut down on travel time. But the forecasted increase in stormy weather and the consequences of a sea level rise for ports make it unlikely that shipping will belong to the winners of climate change.

\section{INTERNATIONAL CLIMATE POLICY AND SHIPPING}

Scientists have warned about a potential impact of human activities and in particular of the burning of fossil fuels on the global climate system for several decades before political negotiations started on an international level in the late 1980s. Today, there is a general consensus on the existence of an anthropogenic warming of the global atmosphere and the necessity of an international climate regime to limit the emission of greenhouse gases, such as carbon dioxide $\left(\mathrm{CO}_{2}\right)$, methane $\left(\mathrm{CH}_{4}\right)$, nitrous oxide $\left(\mathrm{N}_{2} \mathrm{O}\right)$, hydrofluorocarbons (HFCs), perfluorocarbons (PFCs) and sulphur hexafluoride $\left(\mathrm{SF}_{6}\right)$. The most important GHG is carbon dioxide, particularly as exhaust gases from the combustion of fossil energy. The source of GHG emissions growing most quickly are transport services; in the industrialized countries they increased by over 13\% between 1990 and 1998 (UNFCCC 2000).

The FCCC was the launching pad for stronger action in the future. By establishing an ongoing process for review, discussion, and information exchange, the Convention makes it possible to adopt additional commitments in response to changes in scientific understanding and political will. The third conference of parties to the FCCC held in December 1997 in Kyoto, Japan adopted a Protocol with targets for industrialized countries' (so-called Annex B countries) greenhouse gas emissions. These 
targets range from $-8 \%$ for the EU to $+10 \%$ for Iceland compared to 1990 levels by the period 2008 2012. Developing countries have no targets. In July 2001, the part sixth conference of parties was continued in Bonn, Germany (COP 6bis). All crucial questions about the exact design of the four flexible mechanisms in the Kyoto Protocol were resolved and a sufficient number of relevant countries declared that they will now ratify the Protocol. Industrialized countries will thus be enabled to trade emission reductions internationally and use least-cost options for emission reductions on global markets instead of reducing emissions by internal measures.

\section{Impacts of climate change on international shipping}

Climate change is likely to have substantial impacts on the oceans and thus on international shipping (Ittekot 1996). These impacts are not necessarily negative. Both the impacts on infrastructure (port facilities) and ships have to be considered.

Sea-level rise and increased storminess will have enormous impacts on ports. If the current infrastructure at the land/sea interface is to be protected, extremely high costs are to be expected. For example, a it may cost 63 billion US\$ to protect only Japanese ports (Scott 1996, p. 418). Dredging of waterways is already an important cost factor and considered as the most serious environmental

problem for ports. Increased runoff and precipitation will lead to a higher sediment load of rivers. Demands for dredging operations thus can be expected to increase and lead to an increase in costs in ports (Ittekot 1996, p. 275). A sea-level rise, induced by global warming, is unlikely to compensate silting of waterways.

If the frequency and intensity of extreme weather conditions and in particular of tropical storms and cyclones increases, tropical routes become more dangerous, and higher losses can be expected. Weather conditions might force ships to change routes or speed, or to stay longer within protected areas. If the number of lost ships, the damage to ships, or the loss of cargo increases, insurance companies will reflect the higher risk level in their rates or compensation levels. Consequently, ship 
operators will face increase costs in any case: Either due to higher losses or in form or higher insurance fees.

But global warming will also lead to positive effects for international shipping, like the reduction of sea ice. Costs for icebreakers which can amount to annual double-digit million dollar figures for countries like Canada or Russia could be reduced. Both the Northwest passage and the Northern sea route around Russia are likely to be opened up for routine shipping in the next decades. Currently, high insurance costs, the iceberg threat, the need for icebreakers and expensive reinforced hulls, and the extremely short open-water season limit the traffic on Arctic routes. Furthermore, Arctic routes would reduce freight costs from East Asia to Europe considerably (ttekot 1996, p. 282). Ships taking cargo from Rotterdam to Yokohama could cut 5,000 miles, almost cutting travel time in half from the Panama route. Using a route north of Russia similarly nearly halves the time and distance compared to the Suez Canal route between Hamburg and Yokohama (Anonymous 2000). It goes without saying that ship operators will take advantage of these effects while environmentalists may point out the possibility of further damages to these regions.

\section{Factors influencing pollutant emissions by ships}

Freight rates have shown a steady downward trend since the beginning of the 1980s, and sometimes freight rates have not covered the operational costs. Shipowners have developed different strategies to cut costs wherever possible. One way to do this is through registration in open registers. While the majority of all vessel transport is linked to trade between industrialized countries, an increasing share of the merchant tonnage is registered outside of the main trading countries, in open registers. Since the beginning of the 1980 s the OECD registered tonnage has declined from $51 \%$ of the world tonnage to $24.4 \%$ by the end of 1999 (Lloyd's Register 2000). A large share of this decline is the result of the introduction of open registers and the OECD flagging-out. Flagging-out aims at minimizing operational costs and regulatory requirements. While it helps shipowners from OECD countries to compete on the global market, it promotes a race towards substandard shipping. 
In addition to flagging-out, shipowners have passed their responsibility for asset marketing and dayto-day operation to ship management organizations. In many cases the focus of such a management company is on commercial aspects, neglecting aspects related to the safe operation of the ship (Nieuwpoort/Meinders 1998). Cost cutting has induced reckless loading practices in ports and operation at a higher speed, sometimes beyond permissible design limits.

Over the last 35 years remarkable improvements in fuel efficiency have been achieved, for instance by engine optimization. However, the highest priority for potential shipowners is the capacity and the speed of the vessel. Energy efficiency and environmental impact are of minor importance as long as no conflict occurs with international or regional legislation over the ship's lifetime, or as long as there are no economic incentives (e.g. graded port fees, taxes etc.).

GHG emissions from ship operations are often linked with emissions of other pollutants that create important environmental problems. Table 1 gives an overview of these links.

Table 1: $\quad$ Gaseous pollutants from ships and its environmental effects

\begin{tabular}{|c|c|c|c|c|c|c|c|}
\hline \multicolumn{8}{|l|}{ POLLUTANTS } \\
\hline CONSEQUENCES & SOx & NOx & VOCs & $\mathrm{CO}_{2}$ & CFCs & Halons & $\mathrm{CH}_{3} \mathrm{Br}$ \\
\hline Greenhouse effect & & & & $x$ & $x$ & $X$ & \\
\hline Ozone-stratospheric & & & & & $x$ & $x$ & $X$ \\
\hline Ozone-ground level & & $x$ & $x$ & & & & \\
\hline Acid rain & $x$ & $X$ & & & & & \\
\hline Linked-up with: & & & & & & & \\
\hline Fuel combustion & $X$ & $x$ & $x$ & $x$ & & & \\
\hline Cargo handling & & & $x$ & & $x$ & & $x$ \\
\hline Ship's equipment & & & & & $x$ & $X$ & \\
\hline Incinerators & $X$ & $X$ & & $X$ & & & \\
\hline
\end{tabular}




\section{Maritime Transport in the FCCC process}

International bunker fuel emissions shall not be reported under the national emissions and are excluded from any commitment in the Kyoto Protocol. However, prior to Kyoto in 1996, a discussion on the allocation of bunker fuels was started in the international climate negotiations but did not lead to any results. Despite the exclusion from national targets Article 2, paragraph 2 of the Kyoto protocol states: "The parties included in Annex I shall pursue the limitation or reduction of greenhouse gases not controlled by the Montreal Protocol from aviation and marine bunker fuels, working through the International Civil Aviation Organization and the International Maritime Organization, respectively".

Over the last decades, IMO has adopted several rules and regulations to improve the environmental and safety situation of maritime transportation. IMO's activities concerning environmental issues have so far centered on marine pollution. Emissions into the air have only lately come in and have been under consideration of the Marine Environment Protection Committee (MEPC) since 1990. IMO member states have signed Annex $\mathrm{VI}$ of the MARPOL Convention, providing a regulatory framework for the prevention of a variety of air pollutants from ships. However, Annex VI that has not entered into force yet does not address $\mathrm{CO}_{2}$.

Although IMO was successful in producing standards, it was less successful in ensuring their application and enforcement (Nieuwpoort/Meinders 1998). This lack of the necessary executive power is hampering the adoption of environmental measures to control air emission in the shipping industry. There are currently no real economic incentives for shipowners to invest in low-polluting ships or in additional environment-friendly equipment of existing ships as non-compliance reduces the annual operating costs by 13-15\% (OECD 1996). Therefore, it is obvious that Annex VI to the MARPOL will not have any major effect on reducing emissions of sulfur and nitrogen oxides in the foreseeable 
future (Kågeson 1999). This means that enforcement powers are necessary if IMO is going to play a role in setting climate policy instruments.

As mandated by resolution 8 , adopted by the Conference of parties to MARPOL $73 / 78$, and by the Kyoto Protocol the MEPC at its 42nd session agreed to invite the Secretariat of IMO to commission a study concerning greenhouse gas emissions from ships. The MEPC commissioned a study on the greenhouse gas emissions by ships in September 1999 (IMO 1999b), and a final report (IMO 2000a) was submitted to the IMO in March 2000. The report examines greenhouse gas emission reduction possibilities through different technical, operational, and market-based approaches. At MEPC`s 46. Meeting in April 2001 Norway submitted an information on mechanisms to curb greenhouse gas emissions (IMO 2001a). The MEPC agreed to establish a Working Group at the next session in March 2002 to evaluate proposals for greenhouse gas emissions reduction, to draw up a work plan and to prepare materials for consideration in developing an IMO strategy for greenhouse gas reduction

\section{IMPLEMENTATION OF CLIMATE POLICY CONCERNING INTERNATIONAL SHIPPING}

The starting point of a coherent concept to reduce GHG emissions from international shipping is the formulation of political objectives. Compared to other sources of GHG emissions, the introduction of effective and efficient policies for maritime transport is maybe the most complex task of the Kyoto process. The distinct characteristics of the industry have to be considered in order to find the most practical solution to global GHG emissions reduction:

? While the FCCC and the Kyoto Protocol are based on responsibilities assumed exclusively by nation-states, mainly Annex B countries, maritime transport services are provided by a global industry and take place outside of national control.

? The importance of transportation as an accelerator of economic growth, and the decentralized, mobile characteristics of emission sources limit even the introduction of effective domestic climate policies for land-based vehicles. Furthermore, almost all energy- 
intensive industries operating in international markets currently are fully exempted or pay reduced emissions or energy taxes.

? The impact of ship emissions on local and regional air quality will continue to be the dominant policy driver (IMO 2000a). In European waters for instance, $\mathrm{SO}_{2}$ and $\mathrm{NO}$ x emissions from ships represent 30\% to 40\% of the planned total EU emissions in 2010 (Davis et.al. 2000, p. 49). A contribution of shipping, beyond the expected results of MARPOL's Annex VI requirements, might close the gap between the environmental standards for other transport modes, the available technological solutions and their application on seagoing vessels. It thus may be possible to combine climate policy and reduction of local and regional pollutants.

? Shipping has the potential to provide the most environmentally sound transport services. Nevertheless the industry has currently no incentive to use its potential for substantial GHG emission reductions. The induced costs to exploit these opportunities are feared to limit the (cost-) competitive advantage of shipping to other modes of transport.

\section{Allocation of emissions}

A decisive question is the allocation of emissions and emission reduction objectives to the actual emitters. Corresponding to the Kyoto Protocol, objectives should be focused on quantitative emission levels. Practical allocation approaches, as well policy objectives, depend to a large extent on the applied policy instruments and their mechanism for motivating emitters in the shipping industry to achieve emission reductions. A number of possibilities are available for allocating bunker fuel emissions. UNFCCC (1996) lists the following options:

1. No allocation;

2. Allocation of bunker emissions to Parties in proportion to national emissions;

3. Allocation to Parties according to the country where the bunker fuel is sold;

4. Allocation to Parties according to the nationality of the transporting company, the country where the ship is registered, or the country of the operator; 
5. Allocation to Parties according to the country of departure or destination. Alternatively the emissions related to the journey could be shared between the country of departure and the country of arrival;

6. Allocation to Parties according to the country of departure or destination of passenger or cargo. Alternatively, the emissions related to the journey of a passenger or cargo could be shared by the country of departure and the country of arrival;

7. Allocation to Parties according to the country of origin of the passenger or owner of the cargo;

8. Allocation to the Party of emissions generated in its national space.

Options set in italics were stated to be the basis of further discussions and will be discussed below in more detail.

Allocating bunker fuels according to fuel sales (Option 3) is sure to lead to distortions as fuel sales do not correspond to transport shares of the country.

The seemingly easiest equitable way to allocate bunker fuels to national inventories is to split them 1:1 between the country where the ship started its trip and the country where the ship arrived (Option 5). However, this is more complicated than it seems. Often ships first stop in a major port after a long overseas trip and then go on to smaller ports in the area (see Figure 1).

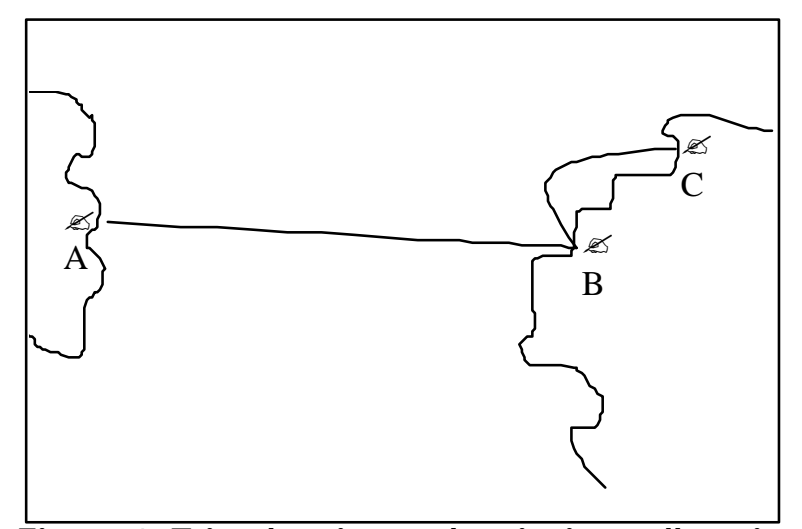

Figure 1: Trip planning and emissions allocation 
A ship travels from port $A$ to port $B$ and then on to port C. $25 \%$ of its cargo is unloaded at port $B$ and $75 \%$ at port C. In the 1:1 allocation, port B's country would be disadvantaged as it would have to bear $50 \%$ of the emissions of both the long trip A-B and the short trip B-C but only get $25 \%$ of the cargo. Port C's country would be advantaged as it would only bear 50\% of the emissions of the short trip BC but get $75 \%$ of the cargo. Emissions per ton of freight would thus be allocated very unevenly.

In order to avoid this problem of unequal allocation, emissions per ton of freight could be shared 1:1 between exporting and importing country (Option 6). This would assume that each shipping company would have to keep records for each ship on:

- exporting country, importing country, amount of freight and transport distance for each shipment of goods

\section{- total emissions}

The reporting has to be on a per-ship basis to account for different degrees of efficiencies of ships. The data would annually be reported to the UNFCCC Secretariat. It is likely that shipping companies would object to this approach due to the high data demands.

Allocation could also be done on the basis of the shipping registries (see Table 5), i.e. the registering country would have to bear the emissions of its fleet. This allocation mode would of course lead to a huge transfer of emissions from Annex B countries into Non-Annex B countries (i.e. countries without emission target) such as Panama and Liberia. 
Table 2: Shares of flag states in the world fleet above $2 \%$ end 1999

\begin{tabular}{lc}
\hline Country & Share \\
\hline Panama & 19.4 \\
Liberia & 10.0 \\
Bahamas & 5.4 \\
Malta & 5.2 \\
Greece* & 4.6 \\
Cyprus & 4.3 \\
Norway* & 4.3 \\
Singapore & 4.0 \\
Japan* & 3.1 \\
China & 3.0 \\
U.S.* & 2.2 \\
Total Annex B & 27.3 \\
\hline
\end{tabular}

*Annex B country

Raw data source: OECD (2000a, Table 12)

Allocation according to the country of origin of the passenger or owner of the cargo (Option 7) would help to integrate potential GHG emission offsets via the transport chain. Despite relatively high transaction costs, this option promotes the polluter-pays principle and supports cost-efficient measures to reduce emissions.

All national allocation approaches raise questions of equity, political acceptability, and, in particular, practical feasibility. However, the view that an integration of international bunkers and emissions into national emissions inventories would require a re-negotiation of emission reduction obligations of Annex B countries under the Kyoto Protocol (IMO 2000a, p. 152) seems far-fetched. Any change in national circumstances then could equally be used as pretext to renegotiate targets. One way to prevent national allocation (Option 1) would be to agree to a worldwide target for marine bunker fuels and make IMO responsible for reaching the target.

\section{Policy instruments and compliance}

The objective of policy instruments has to be the introduction of an effective and efficient stimulus for environmentally sound operational and technical improvements on existing and new ships. The 
application of the polluter-pays-principle is of highest priority, in correspondence with a utilization of the available potential of cost-efficient options to reduce GHG emissions and an integration of technical progress. Besides the intended environmental control, stimulation of innovation is one of the key tasks of environmental policies, due to its potential to reduce extra costs for environmental protection. Different policy instruments are considered feasible for a GHG reduction strategy in international shipping:

\section{Emission standards}

Minimum efficiency standards or emission standards are the most established form of environmental policy. They could either be implemented by the IMO, regional, national or local authorities. Within their competencies, these institutions could develop regulations on how much and in what way GHG could be emitted or have to be reduced. Based on the knowledge of the technological state-of-the-art, these regulatory instruments could precisely prescribe emission reduction objectives to individual emitters. Another approach would be to divide the emission of GHG into a legal and illegal portion. The division can be done using an emission ceiling or technical requirements. International shipping has gained substantial experience in finding international solutions to common safety and pollution problems in the form of conventions based on global uniform minimum standards.

Because $\mathrm{CO}_{2}$-emissions from ships are determined both by operational practices and the technical construction of the vessel, standards should ideally cover both (IMO 2000a, p. 154).

However, during the last decade, the inflexibility of regulatory instruments and the high differences of costs per emission reduction unit have led to criticism: Environmental standards are not suitable for differentiating sufficiently between emitters on the basis of their marginal reduction costs. Furthermore, the definition of standards depends on the best available technology. Once defined, standards are generally too inflexible to integrate technological progress as a dynamic factor or even to foster innovation. 
To allow emitters more flexibility and to reduce the cost of emission control, market-based instruments, like tax incentives or environmental charges or tradable permits, are considered as a substitute for standards.

\section{Tax differentiation and environmental charges}

In several Annex B countries, environmental taxation schemes are the most important elements of national climate policies. Energy taxes promote energy efficiency, while other concepts are directly based on GHG emissions. Compared to standards, taxes and charges introduce no clear emission limit but put a price on emissions. A carbon charge on bunker fuels will give ship owners increased incentives to reduce fuel use and related emissions. The reaction depends on individual ship types, the value of the cargo and the availability of alternative transport modes.

Michaelis (1997) has analyzed an emission tax on bunker fuels in detail. He asked industry representatives about their reactions to tax levels of $\$ 5$, $\$ 25$ and $\$ 125$ per ton of carbon. These would represent about 5 per cent, 25 per cent and 125 per cent of the price for residual fuel oil (at $\$ 90 /$ ton), and 3 per cent, 15 per cent and 75 per cent of marine diesel fuel prices (at \$150/ton). Shipowners and charterers generally did not think that they would be able to pass the charge on by increasing their shipping rates and showed high preferences for avoiding payments by charging fuel offshore. The only maritime fuel tax that ever existed - California introduced a 8.5\% sales tax in 1991 - led to an enormous reduction of fuels sales. Shipowners evaded the tax by fuelling in Panama and it was rescinded in late 1992 (Michaelis 1997, p. 40). This is why any taxation regime has to be implemented globally and needs support from at least a great majority of countries with most important ports. Otherwise, any charge would be limited by the costs for bringing fuel from untaxed sources in international waters for offshore refueling.

Various methods of tax collection are possible (e.g. based on sales of fuel from bunkers to ships, sales from oil companies to bunker dealers, fuel out of the refinery gate) which might influence the ease of implementation, potential for avoidance, and hence greenhouse gas impacts of the measure. 


\section{Emission Trading}

In an emission trading system, the total emission volume is limited to the number of distributed permits. Emitters have to limit their emissions to their permitted volume. In case they want to increase their emissions they have to purchase additional permits, whereas they could sell permits they do not need. Compared to taxes or standards, not the price of emissions or the applicable technology is regulated, but the total emission quantity. Emission trading schemes have been used in the United States to limit $\mathrm{SO}_{2}$-emissions. As flexible instruments, different forms of emission trading are central instruments of the Kyoto Protocol. The different instruments allow joint targets of countries, international trading of emission permits between governments and creation of emission permits through joint projects between private or public organizations in different countries. Such projects are called "Clean Development Mechanism" (CDM) if the project is hosted by a developing country without an emissions target and are otherwise known as "Joint Implementation". Detailed rules and guidelines for the use of these mechanisms are currently being negotiated.

Emissions trading systems for shipping can be administrated at different levels. The level depends on the allocation mode. Allocation to national inventories would be possible but difficult as was shown above. Another possibility would be the establishment of a restriction (cap) on total emissions from international shipping under the auspices of IMO or others. As for Annex I countries, a cap for 200812 would have to integrate the anticipated growth rate and would be expressed in the relation of the expected emission from shipping to its 1990 levels (i.e. ...should not exceed $X$ \% ...). The negotiations about an emission cap could take place within the IMO, since almost all parties to the Kyoto Protocol are members of the IMO. According to Norway it would be a demanding task to achieve an agreement on the size of a cap on total emissions from shipping (IMO 2001a, p 4) but one the other hand one has to recall the international climate negotiations that where very demanding, too, but nevertheless successful.

Finally, emissions could be allocated to single emitting ships (i.e. their owners). They could then be allocated permits for free (grandfathering) or have to buy them in an auction. Ship owners choosing to over-comply could sell surplus permits on the market. 
It would also be possible for countries with targets to invest in emissions reduction projects in shipping and to get emission credits. If there is an overall cap for international shipping, such projects should be treated like Joint Implementation. The emission reduction achieved through the project would be deduced from the cap.

Even if there is no cap at all for the international shipping sector projects that reduce shipping emissions could be credited similarly to CDM projects. They then would have to calculate baseline emissions for what would have happened without the project and get a certificate by an independent, accredited certifier to receive emission credits.

\section{Voluntary agreements}

Voluntary agreements are the result of negotiations between the government and an industry or a company on strategies to control environmental problems. They are a popular policy tool in many Annex B countries' energy-efficiency and climate-change policies. Voluntary agreements can range from declarations of intent, to binding contracts with industry, with penalties specified in the case of non-compliance. In most cases, there is an implicit or explicit threat from the regulator to impose other policy instruments if the company/industry is unwilling to negotiate.

In the shipping industry, a voluntary agreement could focus on the adoption of emission or efficiency standards, certain approved practices or prescribed actions or to report emissions or efficiency levels and to describe any actions being taken to improve them. Voluntary agreements with ship-builders and operators are, of course, another option to reduce greenhouse gas emissions. However, given the patchy performance of voluntary agreements in a national context, they are unlikely to go beyond business-as-usual in the context of an international sector with strong competition, as is the case in international shipping.

\section{Environmental indexing}

In an environmental indexing system, a voluntary or compulsory label or index is used to indicate the environmental performance of the ship. The index given to a vessel can be used to differentiate taxes, 
port dues and charges, but also insurance rates. Different financial conditions may be differentiated on the basis of an indexing system. So far, indexing systems have only been introduced to a limited extent. In 1998 Sweden introduced measures to reduce ships' nitrogen oxide emissions, i.e. by the installation of catalytic converters, and to promote the use of low-sulfur bunker fuel. Environmentally differentiated fairway and harbor dues shall provide an economic incentive to stimulate the ferry traffic and other frequent vessel traffic to and from Swedish ports. An other example is the Rotterdam Green Award Foundation. The Green Award is a voluntary certificate, based on high environmental and safety standards. Qualified ships get discounts on port dues, pilot fees etc. The most comprehensive indexing system was developed in Norway and presented to the MEPC 1995. It has never been implemented internationally but has initiated a differentiation of shipping dues in Norway from January 2000. The problem arises that GHG emissions are only one factor among a multitude of others that influence overall environmental performance of ships.

An internationally accepted system for creating incentives for GHG emission reductions depends on a co-operation of potential bonus providers, ship owners and classification societies. A voluntary system for cleaner ships has no effect on old and low efficient ships, but reduces the current economic disadvantage of clean ships.

\section{Strategic options for IMO}

Economic research has proven that the application of policy instruments on local, national, regional or international levels had to be adjusted to specific conditions and is often influenced by political interests, leading up to a reduction of their economic and/or environmental efficiency far below their theoretical potential. A successful environmental policy does normally depend on a single instrument than on the integration of a new instrument in a coherent policy framework with a strategic focus and a cooperative policy style (Klemmer et al. 1999, p. 110). In such a strategic concept, standards are often considered basic instruments for ensuring a minimum contribution by every emitter to an overall policy objective, while market oriented instruments provide economic incentives for additional 
investments in environmentally sound technical or operational measures and to set a counterweight to "grandfather clauses".

Table 3 gives an overview about the potential contribution of individual instruments towards a strategic climate policy concept for international shipping

Table 3: Evaluation of policy instruments to achieve GHG emission reduction objectives

\begin{tabular}{|c|c|c|c|c|c|}
\hline $\begin{array}{l}\text { Instrumental focus to } \\
\text { reduce emissions }\end{array}$ & \multicolumn{2}{|c|}{ Technology \& Operation } & \multicolumn{2}{|c|}{ Price differentiation } & Emission ceilings \\
\hline Function & $\begin{array}{l}\text { Allowed emiss } \\
\text { application of } \\
\text { technology }\end{array}$ & $\begin{array}{l}\text { ns depend on the } \\
\text { prescribed level of }\end{array}$ & $\begin{array}{l}\text { the higher } \epsilon \\
\text { higher the cost }\end{array}$ & missions, the & $\begin{array}{l}\text { Emission requires } \\
\text { the purchase of a } \\
\text { licence }\end{array}$ \\
\hline Instruments & $\begin{array}{l}\text { Emission } \\
\text { standards }\end{array}$ & $\begin{array}{l}\text { Voluntary } \\
\text { agreements }\end{array}$ & $\begin{array}{l}\text { Environmental } \\
\text { indexing }\end{array}$ & Taxation & Tradable permits \\
\hline Institutional complexity & high & low & low & Moderate & moderate \\
\hline Environmental Effectiveness & high & low & moderate & Moderate & high \\
\hline Cost efficiency & low & high & high & Moderate & high \\
\hline Dynamic efficiency & low & low & moderate & high & high \\
\hline $\begin{array}{l}\text { Level of application } \\
\text { Conformity with MARPOL VI }\end{array}$ & global/ regional & $\begin{array}{l}\text { global / regional } \\
\text { moderate }\end{array}$ & decentral & global / regional & global \\
\hline
\end{tabular}

The IMO Study of Greenhouse Gas Emissions from Ships (IMO 2000a, p. 165) proposes the following strategy for policy implementation for IMO: To first explore the interests for entering into voluntary agreements on GHG emission limitations between the IMO and the ship owners, or to use environmental indexing. This recommendation is strange as the study also states that "Voluntary agreements were not found to be a viable approach to obtain significant global GHG emissions reductions from international shipping“ (IMO 2000a, p. 21), and that „Environmental indexing does not seem to be a very efficient tool to reduce emissions, even if some reductions may be achieved on voluntary basis" (ibid, p. 164). Second, start working on how to design emission standards for new and possibly also existing vessels. Third, pursue the possibilities of credit trading from additional abatement measures. From the authors' point of view, this strategy would help with ratification of the Kyoto Protocol, and in the short term could contribute to the implementation of some of the cheapest abatement measures on new and existing ships. 
These recommendations are rather modest and do certainly not fulfil the aim of integrating international shipping in climate policy. Their implementation would mean that emission growth from shipping could continue unchecked. Indeed, the shipping sector would be treated like developing countries as it would not have a distinct emissions target. Voluntary agreements would only be a very small step towards a specific participation of the shipping sector. IMO would not have any "teeth" to credibly threaten with stronger policy instruments given its lackluster performance of implementation of existing standards.

From the environmental point of view, however, a cap on emissions from international shipping is most desirable since total GHG emissions have to be limited (in the long run) if atmospheric $\mathrm{CO}_{2}$ concentrations are to be stabilized (UNFCCC 2001 p. 12). The arguments against an emission trading system under the supervision of IMO are superficial - the difficulties would not be much higher than in the context of a domestic emission trading system. Also the argument that a carbon tax would not be feasible is not valid in the case of low tax rates.

But for the time being, the only real activities under such a regime would be through CDM type projects. They would set a financial incentive for GHG reduction that would be much more effective than any voluntary agreement. However, there would be problems in baseline determination (Michaelowa/Fages 1999) and check of economic additionality (Langrock et al. 2000) of a project. Their magnitude would be similar to those encountered in other sectors.

Wet CDM: First step towards integration of international shipping into international climate policy

Against the background of the difficulties to introduce climate policy instruments into international shipping as described above, the adoption of the CDM model for non-Annnex I countries could be a first and easy step to start (IMO 2001a, p. 1). A definition of a cap for the commitment period after 2012 remains desirable. This project-based emission offsets could start immediately after an agreement was reached and might inaugurate emission trading to the transport industry. Due to the 
possibility of international sales of emission reductions, this might be a win-win solution for the shipping industry. However, it is of crucial importance to note that by applying the CDM, emissions are only reduced compared to a reference scenario of a single project (see Fig. 2). Absolute emissions might still increase depending on the project and baseline under investigation.

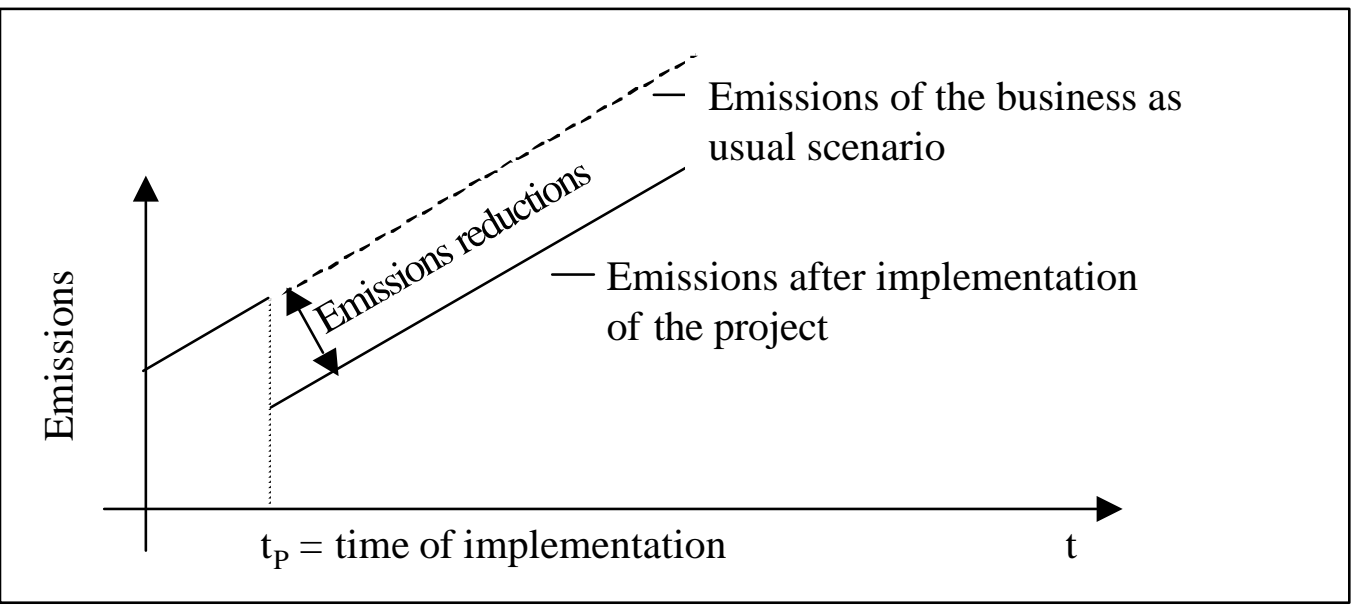

Figure 2: Quantifying emission reductions with absolute emissions rising

Furthermore, one has to keep in mind that each Certified Emission Reduction (CER) generated by an CDM-project increases the industrialized emission target as shown in Fig. 3.

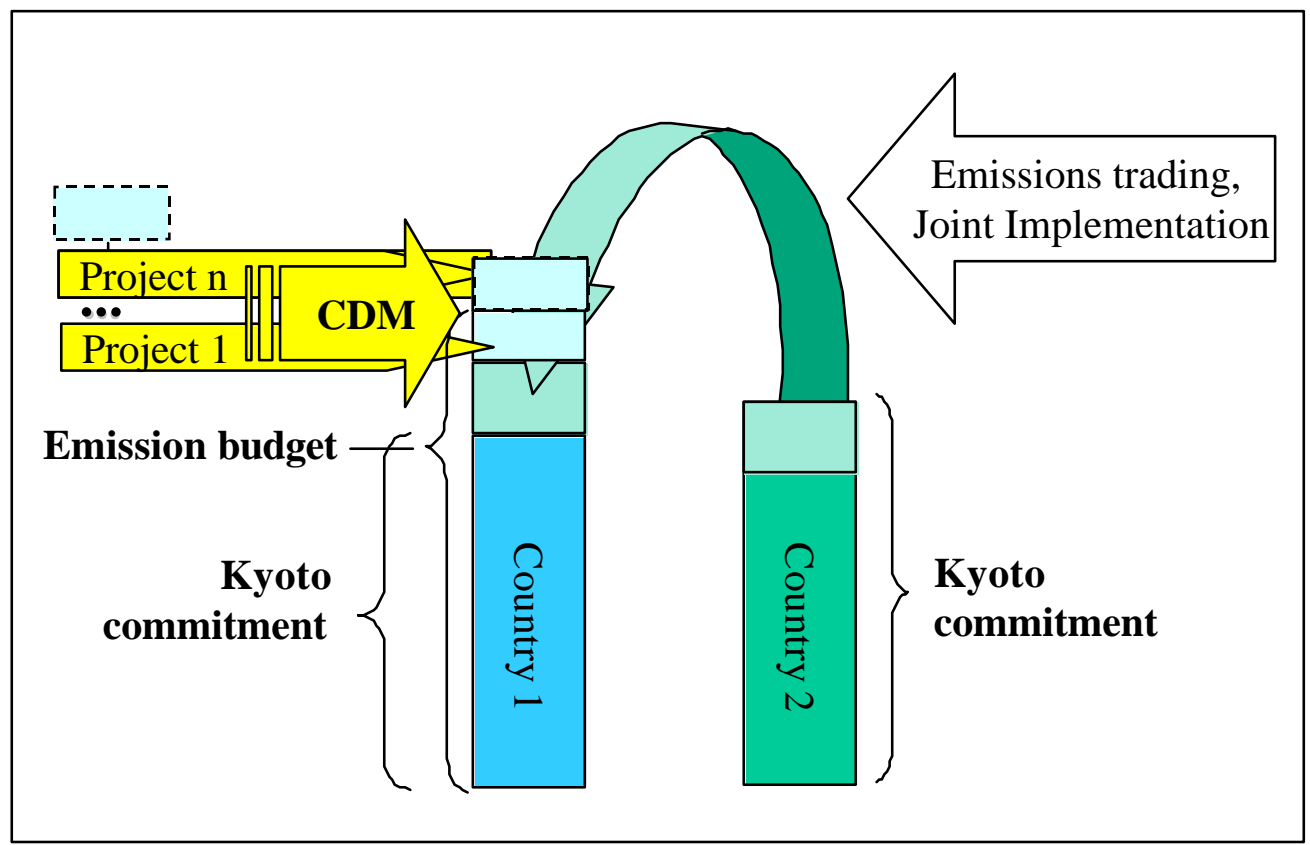

Figure 3: Flexible mechanisms under the Kyoto-Protocol 
Since both, investor and host of project have an incentive to overstate GHG reductions it is absolutely necessary to have a surveillance by an independent third party. Figure 4 illustrates the potential structure of CDM-like projects in the international shipping industry.

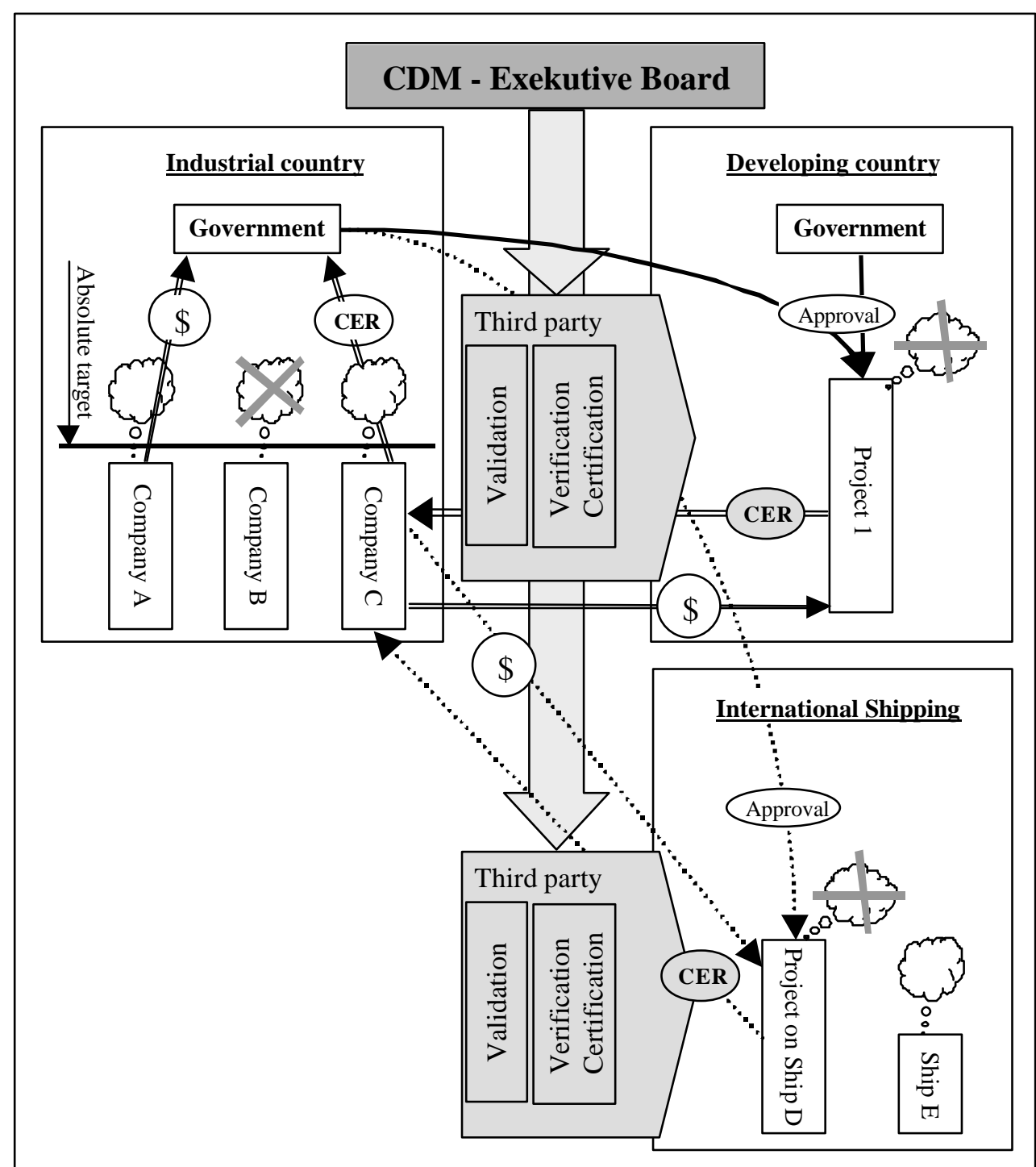

Figure 4: Schematic structure for integrating international shipping into the climate regime

A big advantage of the shipping industry in the context of CDM projects is due to the existence of organizations for controlling compliance to the requirements of applied policy instruments. The classification societies are already important actors in promoting environmental standards in the shipping industry and will have no problems in fulfilling the rules for CDM certifiers. They control the quality of ship design, the construction and operation period. Their network of surveyors enables the classification societies to take over the certification and regular control of "green ships" during their 
annual surveys. It should be noted that the classification societies would not be the one to set that standard but rather the one to apply the rules developed as part of the international climate negotiations.

There is a great variety of measures to reduce GHG emissions from shipping, that may all qualify as CDM project. Table 4 lists most common technical options:

Table 4: $\mathrm{CO}_{2}$ reduction potential by technical measures

\begin{tabular}{|c|c|c|c|}
\hline Measures new ships & Fuel/ $\mathrm{CO}_{2}$ saving potential & Combined 1) & Total 1) \\
\hline Optimised hull shape & $5-20 \%$ & $5-30 \%$ & \\
\hline Choice of propeller & $5-10 \%$ & & \\
\hline Efficiency optimised & $10-12 \% 2$ & $14-17 \%$ 2) & \\
\hline & $2-5 \% 3)$ & $6-10 \% 3)$ & $15-50 \%$ \\
\hline Fuel switch fuel oil diesel & $4-5 \%$ & & \\
\hline Plant concepts & $4-6 \%$ & $8-11 \% 4$ & \\
\hline Use of sails & $10-20 \%$ & & \\
\hline Machinery monitoring & $0.5-1 \%$ & & \\
\hline Measures existing ships & & & \\
\hline Optimal hull maintenance & $3-5 \%$ & $4-8 \%$ & \\
\hline Propeller maintenance & $1-3 \%$ & & \\
\hline Fuel injection & $1-2 \%$ & $5-7 \%$ & \\
\hline Fuel switch fuel oil $\mathscr{s}$ diesel & $4-5 \%$ & & $4-20 \%$ \\
\hline Efficiency rating & $3-5 \%$ & $7-10 \% 4)$ & \\
\hline Eff. Rating + TC upgrade & $5-7 \%$ & $9-12 \% 4)$ & \\
\hline \multicolumn{4}{|c|}{$\begin{array}{l}\text { 1) Where potential for reduction from individual measures are well documented by different sources, potential for } \\
\text { combination of measures is based on estimates only }\end{array}$} \\
\hline \multicolumn{4}{|c|}{ 2) State of art technique in new medium speed engines running on heavy fuel oil } \\
\hline \multicolumn{4}{|c|}{ 3) Slow speed engines when trade-off with NOx is accepted. } \\
\hline \multicolumn{4}{|l|}{ 4) Including fuel switch. } \\
\hline Sources: IMO (2000a, p. 14), Mic & р. 693) & & \\
\hline
\end{tabular}

For example, an investor may decide to switch fuel from residual oil to diesel. In terms of $\mathrm{CO}_{2}$ emission, this fuel is superior due to its higher heating value and due to its lower carbon content. Table 5 summarizes important project characteristics: 
Table 5: Emission reductions by fuel switch from residual oil to diesel

\begin{tabular}{lcccccc}
\hline & $\begin{array}{c}\text { Costs } \\
\$ / \mathrm{t}\end{array}$ & $\begin{array}{c}\text { Carbon } \\
\text { Content (\%) }\end{array}$ & $\mathrm{HV}(\mathrm{kJ} / \mathrm{g})$ & $\begin{array}{c}\text { Mass for } \\
\text { equivalent } \mathrm{HV}(\mathrm{kg})\end{array}$ & $\begin{array}{c}\text { Costs } \\
(\$ / \mathrm{HV} \text { eq })\end{array}$ & $\begin{array}{c}\mathrm{CO}_{2} \text { Emissions } \\
(\mathrm{Kg} / \mathrm{HV} \text { eq })\end{array}$ \\
\hline $\begin{array}{l}\text { Residual } \\
\text { oil }\end{array}$ & 180 & 89,1 & 40,5 & 1000 & 180 & 3564 \\
Diesel & 250 & 86,7 & 43 & 942 & 235,5 & 3267 \\
Difference & & & & & 54,5 & 297 \\
\hline
\end{tabular}

Economic analysis of this project must, however, not only take into account direct cost but rather consider indirect effects as for example lower investment costs, reduced maintenance requirements and higher reliability for diesel engines. Furthermore, the net load capacity is extended what can also help to reduce costs. The contribution of revenues from sale of CERs to the overall finance of the project is strongly dependent on the world market price for emission allowances.

On the other hand, energy intensity can also be improved by operational changes such as a general introduction of GPS and the use of computers to optimize routing and scheduling. An other option is to lower design speed of new-build ships. A halving of maximum speeds will reduce motor power needed by about a factor of ten in the case of tankers, dry bulk and container ships and more than 20 for general cargo ships (IMO 2000a, Appendices p. 41, 46, 49, 52). 
Table 6: Emission reductions by lowering travel speed

\begin{tabular}{|c|c|c|c|c|}
\hline & Dimension & Fast Ships & Slow Ships & Change \\
\hline Number of Ships & & 5 & 6 & +20 \\
\hline Service Speed & $\mathrm{kn}$ & 16 & 12.63 & -21 \\
\hline \multicolumn{5}{|l|}{ Emission Parameters } \\
\hline Main Engine Power / Ship & KW & 13250 & 5800 & -56 \\
\hline $\begin{array}{l}\text { Fuel burned on all Ships } \\
\text { Annually }\end{array}$ & $\mathrm{t}$ & 71460 & 45180 & -37 \\
\hline $\mathrm{CO}_{2}$ emitted per $\mathrm{t}$ and $\mathrm{nm}$ & g/t.nm & 3.590 & 2.250 & -37 \\
\hline $\mathrm{SO}_{2}$ emitted per $\mathrm{t}$ and $\mathrm{nm}$ & g/t.nm & 0.086 & 0.054 & -37 \\
\hline NOx emitted per $t$ and $n m$ & g/t.nm & 0.092 & 0.057 & -37 \\
\hline \multicolumn{5}{|l|}{ Principle Demension of Ship } \\
\hline Length between Perpendicles & $\mathrm{m}$ & 260 & 248.6 & \\
\hline Breadth & $\mathrm{m}$ & 32.2 & 31.4 & \\
\hline Draft & $\mathrm{m}$ & 12.9 & 12.9 & \\
\hline Displacement & $\mathrm{t}$ & 87550 & 82740 & -5 \\
\hline
\end{tabular}

Ships have been designed following an optimisation procedure by Lee (1983). Ships are designed for minimal required freight rate.

As can be seen in Table 6 the potential to reduce emissions by lowering travel speed while keeping the total capacity constant is quite substantial. But it is quite difficult to quantify costs. Of course they are reduced due to decreased fuel consumption and lower investment costs. On the other hand they rise due to increased number of employees required on the ships. Lowering speed is equal to increase stocks and results consequently in higher costs for fixed capital. The significance of the latter aspect depends heavily on the kind of goods transported.

Table 7 provides an overview on other operational measures, that may qualify as CDM-project. 
Table 7: $\mathrm{CO}_{2}$ reduction potential by operational and design measures

\begin{tabular}{|c|c|c|c|}
\hline Measures & Fuel/ $\mathrm{CO}_{2}$ saving potential & Combined 1) & Total 1) \\
\hline \multicolumn{4}{|c|}{ Operational planning / Speed selection } \\
\hline Fleet planning/lower speeds & $5-40 \%$ & \multirow{4}{*}{$1-40 \%$} & \multirow{12}{*}{$1-40 \%$} \\
\hline "Just in time" routing & $1-5 \%$ & & \\
\hline Weather routing & $2-4 \%$ & & \\
\hline Misc & ellaneous measures & & \\
\hline Constant RPM & $0-2 \%$ & \multirow{5}{*}{$0-5 \%$} & \\
\hline Optimal trim & $0-1 \%$ & & \\
\hline Minimum ballast & $0-1 \%$ & & \\
\hline Optimal propeller pitch & $0-2 \%$ & & \\
\hline Optimal rudder & $0-0.3 \%$ & & \\
\hline \multicolumn{3}{|c|}{ Reduced time in port } & \\
\hline Optimal cargo handling & $1-5 \%$ & \multirow[t]{2}{*}{$1-7 \%$} & \\
\hline Optimal berthing, mooring and anchoring & $1-2 \%$ & & \\
\hline
\end{tabular}

\section{CONCLUSIONS}

The contribution of international maritime transport to anthropogenic climate change is just beginning to be perceived as an important issue. Ongoing research and political pressure can be expected to raise the importance of this issue in the near future. An early recognition of the potential implications of climate change to the shipping industry could help to reduce the adaptation costs - as an industry with a vulnerability towards changing climate conditions and as a polluting industry without any reduction commitments. Given the growing attention to air pollution emissions from vessels and the potential high costs of reductions, the shipping industry might look to experiences from other industries which have already implemented efficient environmental standards.

$\mathrm{SO}_{2}$ and $\mathrm{NOx}$ emissions are currently the most important environmental problems in the shipping industry. Even without any direct technical reduction option for $\mathrm{CO}_{2}$, instruments could easily try to address the different forms of pollution together. GHG reductions could easily be integrated into the criteria for green / clean ships under the Green Award in Sweden. Comprehensive calculations for numerous measures for reducing sulfur and nitrogen oxides show the cost-effectiveness of reducing emissions from ships (Kågeson 1999). 
Shipping might be the most complex area for climate policy due to several factors. First, extreme competition has led to flagging-out and thus widespread substandard shipping. This makes implementation of climate policy instruments very difficult. Free riding is easy due to the global dimension of shipping and ease of avoiding fuel taxes. However, the growing share of shipping in global GHG emissions and the total absence of any action makes the introduction of measures necessary. The IMO study is grossly lacking in this respect. The optimal strategy would be for IMO to agree on a global shipping emissions target that would be comparable to targets of industrialized countries under the Kyoto Protocol. The target would be allocated to shipowners, and they could engage in Joint Implementation and international emissions trading. If IMO is not able to agree to such a target, CDM projects could still be implemented. A minimum measure would be that governments pressure the industry to enter into voluntary agreements. Domestic measures are also possible. For example countries with major competitive ports could try to differentiate port fees according to the emissions intensity of the ships. 


\section{References}

Anonymous (2000) New York Times, July 29, 2000, Internet:

http://www10.nytimes.com/library/national/science/072900sci-environ-canada.html, accessed: 04 August 2000

Buro, Thomas (2000) Future global transport: air cargo - fast ship - airship, URL: http://www.stud.uniwuppertal.de/ ua0273/, accessed 29 December 2000

Davies et al (2000) Study on the economic, legal, environmental and practical implications of a European Union System to reduce ship emissions of $\mathrm{SO}_{2}$ and $\mathrm{NO}$, London

Det Norske Veritas (1999) Technical report World Bank - ILUMEX lessons learned, Report 99-3287, revision No. 01, Oslo

IMO (2000b) Prevention of air pollution from ships, Consideration of an IMO strategy for greenhouse gases reduction, MEPC 45/8/3, New York

IMO (2000a) Prevention of air pollution from ships, Report on the outcome of the IMO Study on Greenhouse Gas Emissions from Ships, MEPC 45/8, New York

IMO (1999b) Prevention of air pollution from ships, Progress report on follow-up activities, MEPC 43/10/2, New York

IMO (1999a) Draft resolution on sulphur content monitoring, MEPC 43/10/1, New York 
Ittekot, Venugopalan (1996) Oceans, in: Watson, Robert, Zinyowera, Marufu, Moss, Richard (eds.): Climate change 1995: impacts, adaptations and mitigation of climate change: scientific-technical analyses, Cambridge, 269-288

Kågeson, Per (1999) Economic instruments for reducing emissions from sea transports, Air Pollution and Climate Series No 11 / T \& E Report 99/7, Solana

de Keyzer, Cornelius (2000) The EROS demand for Shipping, Presentation of Cornelius de Keyzer for Port of Rotterdam on the Green Shipping Conference, Hamburg 16/17 February 2000

Klemmer, Paul, Lehr, Ulrike and Löbbe Klaus (1999) Umweltinnovationen - Anreize und Hemnisse Innovative Wirkungen umweltpolitischer Instrumente, Band 2, Berlin

Langrock, Thomas; Michaelowa, Axel; Greiner, Sandra (2000) Defining Investment Additionality for CDM projects - practical approaches, HWWA Discussion Paper No. 106, Hamburg

Lee, K.-Y. (1983) Wirtschaftlichkeitsbetrachtungen beim Schiffsentwurf, Schiffstechnik (30), pp. 68-83

Lloyd's Register (2000), World Fleet Statistics Tables, London

Michaelis, Laurie (1997) Special issues in carbon/energy taxation: marine bunker fuel charges, Annex I Expert Group to the UNFCCC Working Paper No. 11, Paris

Michaelis, Laurie (1996) Mitigation options in the transportation sector, in: Watson, Robert, Zinyowera, Marufu, Moss, Richard (eds.): Climate change 1995: impacts, adaptations and mitigation of climate change: scientific-technical analyses, Cambridge, 681-712 
Michaelowa, Axel; Fages, Emmanuel (1999) Options for baselines of the Clean Development Mechanism, in: Mitigation and Adaptation Strategies for Global Change, 4, 2, p. 167-185

Nieuwpoort, G.; Meijnders, E.L.M. (1998) The integration of economic and safety policy for shipping: The need for self-organisation, in: Haralambides, H.E. (Ed.), Quality Shipping, Market Mechanisms for Safer Shipping and Cleaner Oceans, Rotterdam 1998, 191-216

OECD (2000a) Maritime transport statistics, URL http://www.oecd.org//dsti/sti/transpor/sea/index.htm, accessed Dec. 28, 2000

OECD (2000b) $\mathrm{CO}_{2}$ Emissions from fuel combustion 1971-1998 - Highlights, Paris

OECD (1996) Competitive advantages obtained by some shipowners as a result of non-observance of applicable international rules and standards, Paris

Scott, Michael (1996) Human settlements in a changing climate: impacts and adaptation, in: Watson, Robert, Zinyowera, Marufu, Moss, Richard (eds.): Climate change 1995: impacts, adaptations and mitigation of climate change: scientific-technical analyses, Cambridge, 401-426

Stopford, Martin (2000) The Newbuilding Market, Conference Paper, The Motor Ship - Marine Propulsion Conference 2000, Volume 1, 29th $\& 30^{\text {th }}$ March 2000, Amsterdam, 1-13

U.N. Framework Convention on Climate Change (2001) Climate Change 2001 - The scientific basis, Cambridge 
U.N. Framework Convention on Climate Change (2000) National Communications: Communications from parties included in Annex I to the Convention: Greenhouse gas inventory data 1990-1998, FCCC/SBSTA/2000/11, Bonn.

U.N. Framework Convention on Climate Change (1996) National Communications: Communications from parties included in Annex I to the Convention: Guidelines, Schedule and Process for Consideration: Addendum; Detailed Information on Electricity Trade and International Bunker Fuels, UNFCCC/SBSTA/1996/Add.2, Bonn. 